\title{
Nota científica: Conservação pós-colheita de laranjas Champagne (Citrus reticulata $\times$ Citrus sinensis)
}

\author{
Scientific Note: Post harvest conservation of 'Champagne' oranges \\ (Citrus reticulata $\times$ Citrus sinensis)
}

\section{Autores | Authors}

\section{$\bowtie$ Juliana da Silva AGOSTINI}

Universidade Federal de Mato Grosso (UFMT)

Instituto de Ciências da Saúde Rua Alexandre Ferronato, 1200, Reserva 35, Setor Industrial CEP: $78550-000$ Sinop/MT - Brasil e-mail: juagostini@yahoo.com.br

\section{Silvana de Paula Quintão SCALON}

Universidade Federal da Grande Dourados (UFGD)

Programa de Pós-Graduação em Agronomia CEP: 79804-970 Dourados/MT - Brasil e-mail: silvanascalon@ufgd.br

\section{Caroline Honaiser LESCANO Kesia Esther da SILVA Glaucielli Justen GARCETE}

Centro Universitário da Grande Dourados (UNIGRAN)

Faculdade de Ciências Biológicas e da Saúde

CEP: 79824-900

Dourados/MT - Brasil e-mail: carolhonaiser@hotmail.com kesia_esther@hotmail.com glaujtg@yahoon.com.br

\ Autor Correspondente / Corresponding Author

Recebido / Received: 05/07/2013 Aprovado / Approved: 03/06/2014 Publicado / Published: jun./2014

\section{Resumo}

Objetivou-se avaliar os efeitos de diferentes recobrimentos e temperaturas de armazenamento na conservação de laranjas Champagne. Após refrigeração e sanitização, os frutos foram submetidos aos seguintes tratamentos: 1) controle, sem recobrimento; 2) frutos recobertos com fécula de mandioca a $2 \%(\mathrm{~m} / \mathrm{v}) ; 3)$ frutos recobertos com fécula de mandioca a $4 \%(\mathrm{~m} / \mathrm{v}) ; 4$ ) embalagem com filme de PVC esticável; 5) embalagem em saco plástico de polietileno de baixa densidade. Estes frutos foram, em seguida, armazenados em três diferentes temperaturas: ambiente $\left(25^{\circ} \mathrm{C} / 70 \pm 5 \%\right.$ UR) e em câmara fria a $3^{\circ} \mathrm{C}$ e a $8^{\circ} \mathrm{C}$, com $85 \pm 5 \%$ UR. Determinou-se a perda de massa pelos frutos; no suco, foram determinados o pH e os sólidos solúveis (SS), a acidez titulável, os açúcares totais e o ácido ascórbico. As amostragens foram realizadas a cada 4 dias, durante 24 dias, nos frutos armazenados em condição ambiente, e a cada 10 dias, durante 60 dias de armazenamento, nos frutos mantidos em câmara fria. Os frutos armazenados a $3^{\circ} \mathrm{C}$ apresentaram menor perda de massa. Os frutos do controle e os revestidos com fécula, independentemente da temperatura de estocagem, tiveram perdas maiores do que aqueles embalados em filme de PVC e polietileno. A acidez apresentou redução ao longo do armazenamento em todas as temperaturas estudadas e sem diferenças entre os revestimentos/embalagens. Os tratamentos e o período de armazenamento, independentemente da temperatura, não influenciaram nos resultados de $\mathrm{pH}$, teores de SS, açúcares totais e ácido ascórbico. Os frutos refrigerados a $3^{\circ} \mathrm{C}$ mantiveram a qualidade por até 60 dias, desde que acondicionados com polietileno e PVC, enquanto que, sob a temperatura ambiente, a qualidade dos frutos embalados com estes filmes foi mantida por até 20 dias. Frutos embalados com o filme de polietileno apresentaram sinais de podridão e odor estranho a partir do $20^{\circ}$ dia, quando armazenados a $25^{\circ} \mathrm{C}$, e a partir do $50^{\circ}$ dia, quando armazenados a $8^{\circ} \mathrm{C}$.

Palavras-chave: Armazenamento pós-colheita; Refrigeração; Atmosfera modificada.

\section{Summary}

This study aimed to evaluate the effects of different types of coating, temperatures and storage times in the conservation of 'Champagne' oranges. After cooling and sanitizing, the fruits were submitted to the following treatments: 1) control, 2) coating with $2 \%$ cassava starch ( $\mathrm{m} / \mathrm{v}), 3$ ) coating with $4 \%$ cassava starch $(\mathrm{m} / \mathrm{v}), 4)$ coating with stretchable PVC film and 5) coating with low density polyethylene film. The fruits were stored at three different temperatures: ambient $\left(25^{\circ} \mathrm{C} / 70 \pm 5 \% \mathrm{RH}\right)$ and in cold rooms at $3^{\circ} \mathrm{C}$ and at $8^{\circ} \mathrm{C}$ with $85 \pm 5 \% \mathrm{RH}$. The loss in mass of the fruits was determined and also the $\mathrm{pH}$, soluble solids (SS), titratable acidity, total sugars and ascorbic acid of the juices. Samples were taken every 4 days for 24 days for the fruits stored under ambient conditions, and every 10 days for 60 days for those stored in the cold. The fruits stored at $3{ }^{\circ} \mathrm{C}$ showed a lower mass loss. Regardless of storage temperature, the control fruits and those coated with starch showed higher losses of mass than those coated with PVC and polyethylene. The acidity declined slightly during storage at all temperatures and with all treatments. Independent of temperature, the treatments and storage period had no influence on the $\mathrm{pH}$, solids, total sugar and ascorbic acid contents. Fruit stored at $3^{\circ} \mathrm{C}$ maintained their quality for up to 60 days if packed in polyethylene or PVC, whilst at room temperature, the quality of the fruits packed in these films was maintained for 20 days. Fruits packed in polyethylene film showed signs of rot and a strange odour as from the 20th day when stored at $25^{\circ} \mathrm{C}$, and as from the 50 th day when stored at $8^{\circ} \mathrm{C}$. 


\section{Introdução}

O Brasil se destaca pela ampla produção e exportação de produtos agrícolas; porém, a exportação de frutos cítricos frescos é pouco representativa (INSTITUTO BRASILEIRO DE FRUTAS, 2010). Esse perfil, em parte, deve-se a precariedade de condições de produção e comercialização, elevado volume de perdas na cadeia produtiva, aspecto de qualidade inferior dos frutos $\mathrm{e}$ barreiras fitossanitárias (FISCHER et al., 2009; ZANCHI et al., 2013). Infelizmente, as condições na pós-colheita e que promovem alterações fisiológicas, assim como o ataque por patógenos, limitam o uso do fruto in natura, bem como deprecia seu valor comercial, desencadeando perdas econômicas (NASCIMENTO et al., 2005).

Existem algumas técnicas para reduzir essas perdas, dentre as quais, podem ser citadas: o controle de temperatura e umidade, o uso de embalagens e a aplicação de ceras (OLIVEIRA e CEREDA, 1999). O uso da refrigeração é um dos meios mais eficazes na manutenção da qualidade e na extensão do período de comercialização dos produtos hortifrutícolas; as funções da refrigeração são retardar os processos metabólicos e reduzir a desidratação e a ocorrência de podridões (BRACKMANN et al., 2008). Todavia, pode causar distúrbios fisiológicos, como o dano de frio, caso a temperatura de estocagem dos frutos cítricos seja inferior à Temperatura Mínima de Segurança (TMS) (KLUGE et al., 2007). As frutas cítricas demonstram sensibilidade a baixas temperaturas, que se manifesta por meio da morte de células da casca (pitting), da formação de manchas circulares, das depressões de coloração marrom e das alterações do sabor. A intensidade do dano varia com a temperatura de armazenamento e com o período de exposição (FIORAVANÇO e MÂNICA, 1994; PORAT et al., 2004). Para o armazenamento refrigerado de Iaranja, a temperatura recomendada é $3-9^{\circ} \mathrm{C}$ e UR de $85-90 \%$, com as frutas podendo ser armazenadas durante 3 a 8 semanas, dependendo da cultivar e das condições climáticas (CHITARRA e CHITARRA, 2005). No caso de tangerinas Montenegrina, a refrigeração é $3-5^{\circ}$, com $90-97 \%$ de UR do ar, o que permitiu seu armazenamento por até quatro semanas (BRACKMANN et al., 1999); as tangerinas Clemenules armazenadas a $5^{\circ} \mathrm{C}$ (MALGARIM et al., 2007) e as laranjas Folha Murcha a $7^{\circ} \mathrm{C}$ (TODISCO et al., 2012) puderam ser armazenadas por até 60 dias sem perdas de suas características químicas e de sua qualidade.

Outra forma de manter a qualidade é minimizar as alterações metabólicas provenientes da respiração usando-se atmosfera modificada ( $A M)$, em que o consumo de $\mathrm{O}_{2}$ e a produção de $\mathrm{CO}_{2}$ durante a respiração do produto alteram a composição gasosa do ambiente da embalagem até um novo ponto de equilíbrio, com a criação de uma nova atmosfera gasosa no interior da embalagem.
O efeito será a redução da taxa respiratória e o retardo nos processos bioquímicos que conduzem à senescência, bem como ao desenvolvimento de podridões. Entretanto, atmosferas ricas em $\mathrm{CO}_{2}$ e pobres em $\mathrm{O}_{2}$ prejudicam a qualidade sensorial dos frutos por estimular acúmulo de etanol, acetaldeído e outros compostos voláteis em laranjas (KE e KADER, 1990).

Por isso, o revestimento deve apresentar permeabilidade seletiva adequada, de modo que o produto não entre em anaerobiose ou processo de fermentação, processo comumente verificado em caso de barreira drástica à troca de gases (CHITARRA e CHITARRA, 2005). A regulação dessa atmosfera é dada pelas características fisiológicas do fruto e pela permeabilidade da embalagem (CHITARRA e CHITARRA, 2005; OLIVEIRA et al., 2006). Dessa forma, a seleção de um filme com permeabilidade compatível à taxa de respiração do produto e o controle da temperatura são requisitos importantes para o armazenamento em atmosfera modificada. Malgarim et al. (2007) constataram que tangerinas cv Clemenules acondicionadas em filme de polietileno não perfurados e as revestidas com cera não diluída apresentaram sabor estranho e menor qualidade geral.

Em frutos cítricos, que são não climatéricos, a produção de etileno atua, sobretudo, na mudança de coloração da casca (ASSMANN et al., 2006).

As tecnologias de AM mais usadas em frutos cítricos são os filmes de PVC (ASSMANN et al., 2006), filmes de polietileno (CERETTA et al., 1999; AQUINO et al., 2001; PORAT et al., 2004; MALGARIM et al., 2007), biopolímeros comestíveis de carboidratos (TOGGRUL e ARSLAN, 2004; VALENCIA-CHAMORRO et al., 2009; GALED et al., 2004), lipídios, representados pela cera de carnaúba e similares (VIEITES et al., 1996; CERETTA et al., 1999; HAGENMAIER, 2002) e proteínas (ALLEONI et al., 2006). A fécula de mandioca é um biopolímero comestível usado para dar brilho ao fruto, melhorar a aparência, reduzir a perda de massa e reduzir a intensidade de sua respiração, sem provocar condições de anaerobiose (MANNHEIN e SOFFER, 1996).

Este trabalho objetivou investigar a perda de massa pelos frutos e as alterações nas características físicas e químicas no suco de laranjas Champagne submetidas a diferentes condições de temperatura e revestimentos.

\section{Material e métodos}

Laranjas Champagne maduras, de tamanho médio e em estádio de coloração classificado como C2, de acordo com o Programa Brasileiro para Modernização da Horticultura (HORTIBRASIL, 2011), foram colhidas manualmente em pomar doméstico com 15 anos de idade, em uma propriedade rural do município de Amambaí-MS, em julho de 2009, no período da manhã. 
Após acondicionamento em caixas plásticas, os frutos foram rapidamente transportados em veículos não refrigerados até o laboratório. Inicialmente, estes frutos foram padronizados quanto ao estádio de maturação e à ausência de manchas, doenças e injúrias mecânicas.

Em seguida, esses frutos foram lavados com água e detergente, sanitizados por imersão em solução de hipoclorito de sódio a $200 \mathrm{mg} \mathrm{L}^{-1}$, por 15 minutos. Após a secagem com ar forçado por dez minutos, os frutos foram submetidos a cinco condições de recobrimento/ embalagem: i) controle - sem revestimento ou embalagem; ii) filme PVC esticável com $9 \mu \mathrm{m}$ de espessura; iii) filme de polietileno de baixa densidade com $60 \mu \mathrm{m}$ de espessura; iv) fécula de mandioca a $2 \%(\mathrm{~m} / \mathrm{v})$ gelatinizada, e v) fécula de mandioca a $4 \%(\mathrm{~m} / \mathrm{v})$ gelatinizada.

$\mathrm{Na}$ preparação dos recobrimentos, a fécula de mandioca foi suspensa em água com agitação e sob aquecimento, até atingir $70^{\circ} \mathrm{C}$ e sua geleificação. Em seguida, esta suspensão foi deixada em repouso para resfriar até a temperatura ambiente $\left(25^{\circ} \mathrm{C}\right)$. Os frutos foram imersos por um minuto nesta suspensão, deixados para secar em tela e colocados em bandejas de poliestireno expandido.

O armazenamento dos frutos foi feito em câmaras frias a $3^{\circ} \mathrm{C}\left(85 \pm 5 \%\right.$ UR), $8^{\circ} \mathrm{C}(85 \pm 5 \%$ UR) e em sala climatizada a $25^{\circ} \mathrm{C}(70 \pm 5 \%$ UR). Os frutos armazenados a $25^{\circ} \mathrm{C}$ foram avaliados no início (tempo zero) e a cada quatro dias, por 24 dias. Os frutos armazenados a $3^{\circ} \mathrm{C} \mathrm{e}$ a $8^{\circ} \mathrm{C}$ foram avaliados no início (tempo zero) e a cada dez dias, por 60 dias. Esses frutos foram avaliados quanto à perda de massa fresca (\%) e, no suco, foram avaliados: o pH e os teores de acidez titulável (g $100 \mathrm{~mL}^{-1}$ de ácido cítrico), os sólidos solúveis ( ${ }^{\circ}$ Brix), o ácido ascórbico (mg $100 \mathrm{~mL}^{-1}$ ) e os açúcares totais (g $100 \mathrm{~mL}^{-1}$ ). Além disso, observaram-se tanto as condições externas dos frutos quanto a existência de lesões maiores do que $0,5 \mathrm{~cm}$ que caracterizassem podridões pelo ataque de fungos.

A perda de massa foi determinada por meio de pesagem em balança semianalítica, com os resultados expressos em porcentagem, considerando-se a diferença entre o peso inicial das bandejas contendo os frutos armazenados e aquele obtido a cada intervalo de tempo.

Para avaliação dos parâmetros físicos e químicos, os frutos foram retirados das bandejas e submetidos à extração do suco e sua filtração. A acidez titulável (AT) foi determinada segundo as Normas Analíticas do Instituto Adolfo Lutz (IAL, 2005). O teor de sólidos solúveis e o pH foram determinados por leitura direta no suco homogeneizado, em refratômetro de Abbe ( ${ }^{\circ}$ Brix) e peagâmetro, respectivamente. A determinação do teor de ácido ascórbico (mg $100 \mathrm{~mL}^{-1}$ ) foi feita por titulometria, utilizando-se 2,6-diclorofenol-indofenol (HORWITZ, 1997). O teor de açúcares totais foi determinado pelo método de Lane Eynon (IAL, 2005).
Para cada temperatura de armazenamento, seguiu-se delineamento inteiramente casualizado em esquema fatorial $5 \times 7$, composto de cinco tipos de recobrimento/embalagem, incluindo o controle, e sete períodos de avaliação, incluindo o tempo zero, com quatro repetições. Os resultados das análises de variância e a interação entre os fatores 'embalagem' e 'tempo de armazenamento' foram submetidos à análise de regressão, sendo que as médias das embalagens foram comparadas pelo Teste de Tukey, a 5\% de probabilidade.

\section{Resultados e discussão}

Na avaliação de perda de massa, houve interação significativa entre os fatores 'tempo' e 'embalagens', nas três temperaturas utilizadas $(p<0,05)$. As perdas aumentaram linearmente durante o armazenamento (Figuras 1a, b, c) devido à transpiração dos frutos.

A perda de massa está intimamente ligada à deterioração, uma vez que a perda de água resulta não somente em perdas quantitativas, mas também no prejuízo da aparência (murchamento e enrugamento), na qualidade textural (amaciamento, perda do frescor e suculência) e na qualidade nutricional (VALE et al., 2006).

Os frutos acondicionados sem embalagem (controle) e os revestidos com fécula de mandioca foram os que apresentaram as maiores perdas de massa, nas três temperaturas de armazenamento. Os frutos desses tratamentos - armazenados a $3^{\circ} \mathrm{C}$ por 20 dias - apresentaram um terço da perda de massa apresentada por aqueles armazenados em temperatura ambiente.

Vários trabalhos envolvendo armazenamento pós-colheita de citros têm demonstrado menores perdas de massa fresca para frutos armazenados em ambiente refrigerado. Singh e Reddy (2006) verificaram que, após 17 dias de armazenamento de laranjas Nagpur Mandarin, as perdas de massa em condição ambiente $\left(28^{\circ} \mathrm{C}\right.$ e $58 \%$ UR) e de refrigeração $\left(7^{\circ} \mathrm{C}\right.$ e $78 \%$ UR) foram de $19,4 \%$ e $7,3 \%$, respectivamente; ou seja, na condição de temperatura ambiente, a perda de massa foi quase três vezes maior, sendo que, neste caso, tal resposta justifica-se também pela menor umidade relativa a $25^{\circ} \mathrm{C}$. Nascimento et al. (2006) também observaram que laranjas Pera refrigeradas a $10^{\circ} \mathrm{C}$ tiveram menores perdas de massa do que os frutos armazenados em condição ambiente por quatro semanas, os quais tiveram perdas que chegaram a 29\%. Brackmann et al. (1999), avaliando os efeitos do armazenamento refrigerado $(0,5 ; 3 ; 7 \mathrm{C})$ e UR de 90 - 94\% em laranjas Valência, observaram maior perda de massa $(6,87 \%)$ para os frutos estocados a $7^{\circ} \mathrm{C}$ por 60 dias. Atribuíram tal comportamento à desidratação, decorrente da maior diferença entre as pressões de vapor do interior do fruto e do ambiente externo, e, também, à maior atividade metabólica dos frutos. 

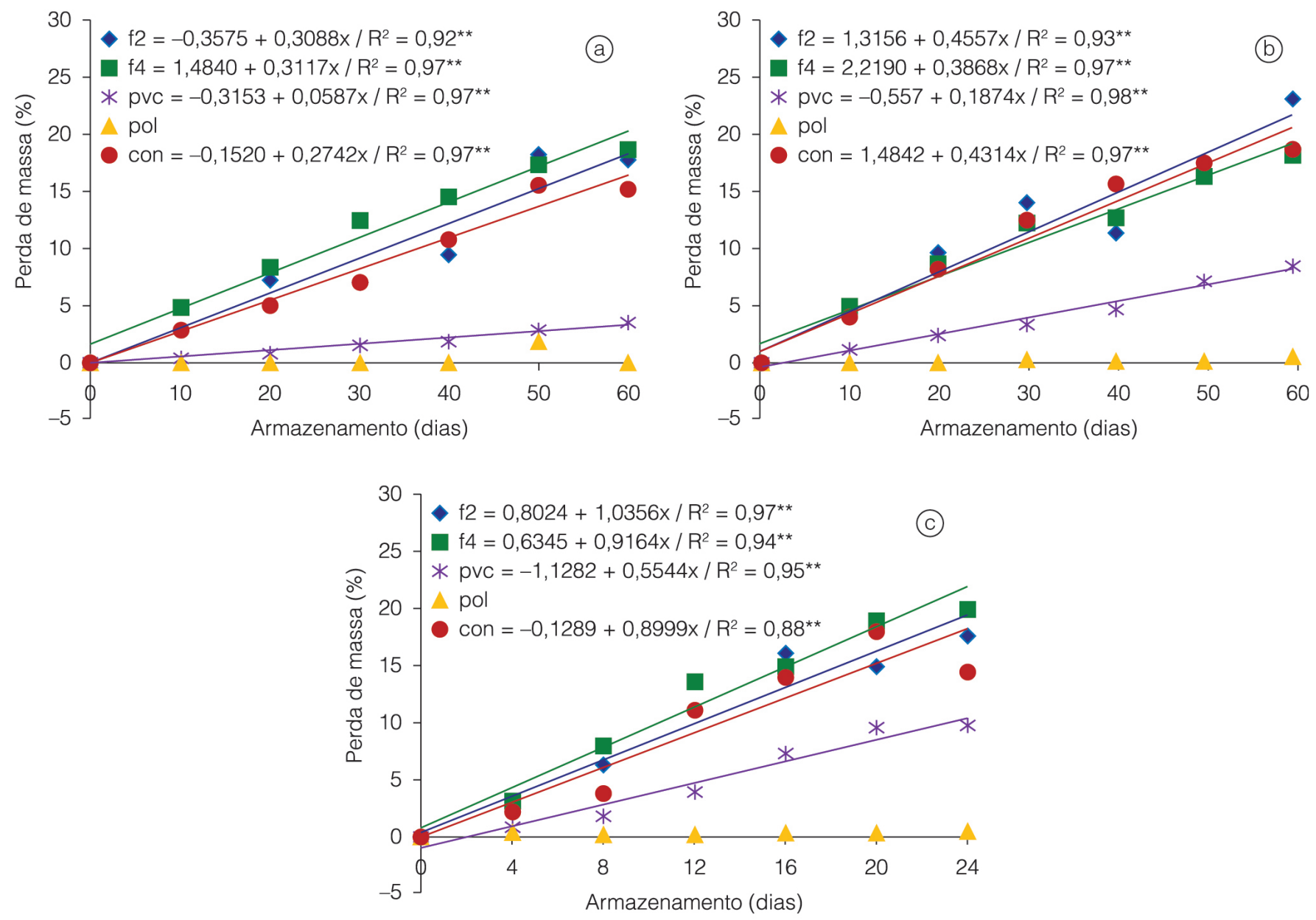

Figura 1. Perda de massa fresca em laranjas Champagne revestidas com fécula de mandioca ou em embalagens plásticas armazenadas sob diferentes temperaturas $\left(a: 3^{\circ} \mathrm{C} ; \mathrm{b}: 8^{\circ} \mathrm{C} ; \mathrm{c}: 25^{\circ} \mathrm{C}\right)$. f2= fécula de mandioca a $2 \%$; 4 = fécula de mandioca a $4 \%$; $\mathrm{PVC}=$ cloreto de polivinila; $\mathrm{pol}=$ filme de polietileno; con=controle, sem embalagem.

O revestimento com fécula de mandioca não foi eficiente em prevenir a perda de massa pelos frutos, pois os frutos com esse revestimento apresentaram perda de massa significativamente igual ou maior do que os do controle, sob refrigeração. Kester e Fennema (1986) descrevem que é mínima a propriedade de barreira à umidade em revestimento à base de fécula de mandioca, devido à sua natureza hidrofílica, e que o retardo na perda da umidade pelo fruto se deve ao fato de estes agentes serem sacrificantes, ou seja, a umidade do gel evapora antes da perda de umidade pelo alimento revestido. Isto explica a maior perda de massa nos frutos com este tipo de revestimento, pois, possivelmente, houve perda de água pelo filme associada à perda pelo fruto. Vieites et al. (1996) concluíram que a película de fécula de mandioca não serviu como barreira protetora para evitar a perda de massa em laranja Pera refrigerada. Em contrapartida, Lermen et al. (2012) constataram perdas de massa mínimas em laranjas armazenadas e protegidas com amido hidrofóbico, mas, neste caso, o efeito positivo deste recobrimento deve-se à baixa permeabilidade deste material à umidade. Observou-se que os frutos protegidos com os filmes de PVC, quando associado às baixas temperaturas, apresentaram perda de massa inferior a um décimo dos frutos controle sob condição ambiente. Além disso, mantiveram a aparência e a turgidez até o final do período experimental. O uso da embalagem de polietileno contribuiu significativamente para reduzir as perdas de massa, menores do que $1 \%$, o que é semelhante ao obtido em tangerinas (MALGARIM et al., 2007), devido à sua menor taxa de permeabilidade ao vapor d'água.

Para Chitarra e Chitarra (2005), os sintomas de murcha com prejuízo na aparência externa ocorrem quando a perda de massa ultrapassa 10\%; note-se que, neste estudo, isso ocorreu após 12 dias de armazenamento para os frutos sem embalagem ou revestidos com fécula; aos 24 dias, nos frutos revestidos com PVC; aos 30 dias, nas laranjas sem embalagem ou revestidas com fécula a $8^{\circ} \mathrm{C}$, e aos 40 dias, quando armazenadas a $3^{\circ} \mathrm{C}$. 
Frequentemente, quando há grandes perdas de massa em frutos, é comum ocorrerem alterações em alguns parâmetros químicos, decorrentes da concentração dos compostos em resposta à perda de água. Mesmo com perdas de água que, em alguns tratamentos deste estudo, atingiram quase 30\%, não foram verificadas alterações significativas em muitos dos parâmetros químicos avaliados nos sucos das laranjas Champagne. Jomori et al. (2003) justificam que a transpiração fica restrita apenas às células da casca, precisamente no flavedo e no albedo do fruto, não interferindo no teor dos constituintes presentes no suco.

Observaram-se sinais de podridão associados a odor desagradável em alguns frutos embalados em polietileno, após 20 dias de armazenamento em condição ambiente, e após 50 dias a $8^{\circ} \mathrm{C}$. Atribui-se esta deterioração à baixa permeabilidade desta embalagem ao vapor de água, o que eleva a umidade relativa, ao redor da fruta embalada, a valores acima de 95\% (GORRIS e PEPPELENBOS, 1992). Isto favorece a condensação de água e, consequentemente, a proliferação de fungos. No caso do odor desagradável, a elevada concentração de $\mathrm{CO}_{2}$, proporcionada pela baixa permeabilidade do material da embalagem aos gases, desencadeia processo de fermentação, com consequente produção de compostos responsáveis pelo off-flavor, como álcool e acetaldeído (KE e KADER, 1990).

Independentemente das condições de temperatura e do tipo de revestimento utilizado, verificou-se que, durante o armazenamento, houve redução de até 32,07\% nos valores de AT até o 12. ${ }^{\circ}$ dia, nos frutos armazenados em condição ambiente, e de $23 \%$ e 24,52\% em 40 dias, nos frutos refrigerados a $3^{\circ} \mathrm{C}$ e $8^{\circ} \mathrm{C}$, respectivamente (Figura 2). Vale ressaltar que esta redução não implica em perda de qualidade do suco, pois foram reduções inferiores a 0,5\%. Segundo Brackmann et al. (1999), a redução nos teores de AT é esperada durante o armazenamento de citros, pois seus ácidos são utilizados para a produção de energia e, eventualmente, para a fermentação alcoólica (LATADO et al., 2008). Em estudos envolvendo armazenamento de frutos cítricos, como limões sicilianos (HENRIQUE e CEREDA, 2007); laranjas Valência (ERKAN et al., 2005); Iaranja Salustiana (CANTILLANO et al., 2009), e laranja sanguínea (RAPISARDA et al., 2001; LATADO et al., 2008), foram verificadas reduções no teor de acidez. No caso da laranja sanguínea, os comportamentos de queda do teor de acidez foram distintos, sendo que, no primeiro
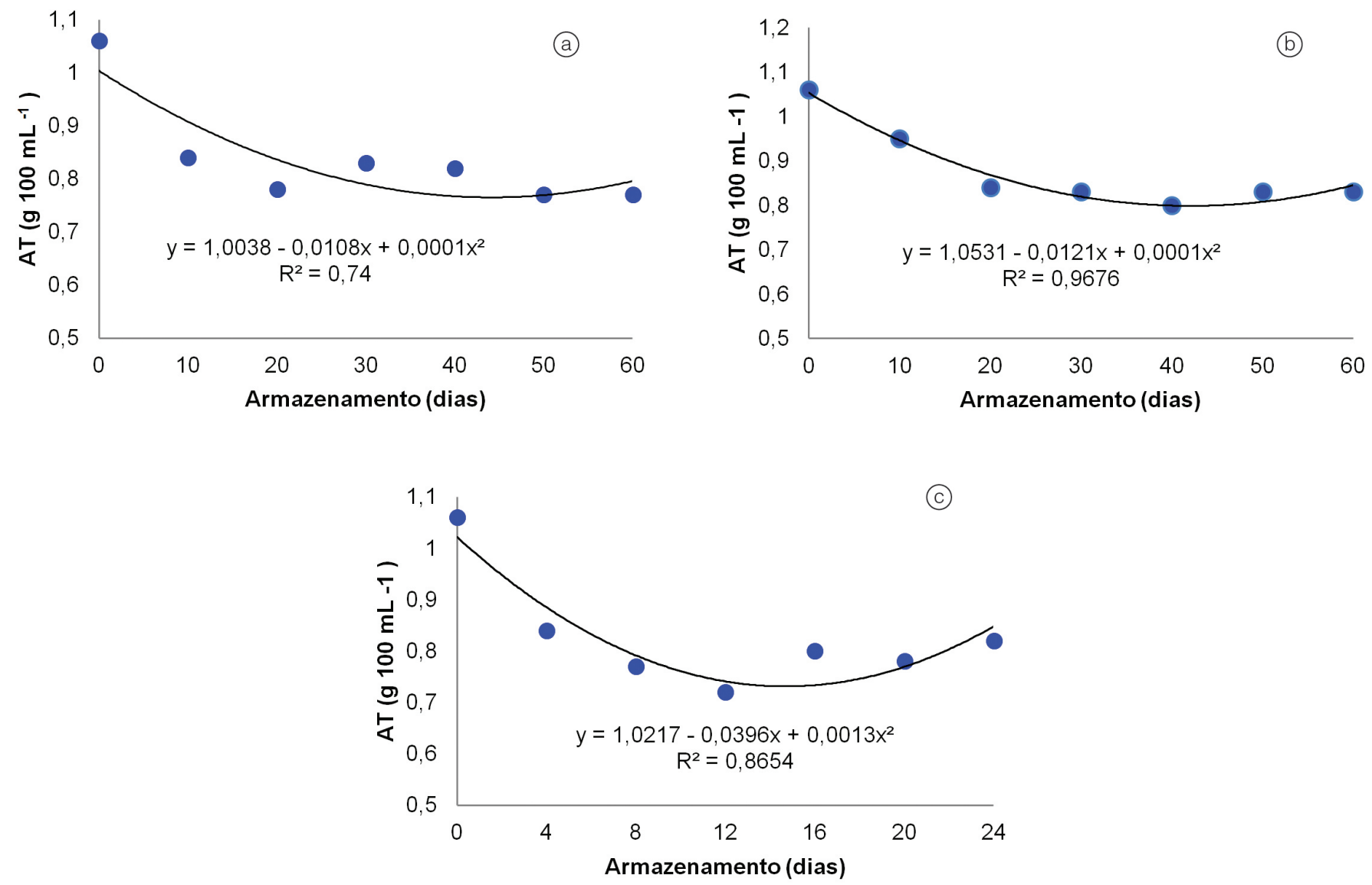

Figura 2. Acidez titulável (AT) em laranjas Champagne revestidas com diferentes proteções e armazenadas sob diferentes temperaturas (a: $\left.3^{\circ} \mathrm{C} ; \mathrm{b}: 8^{\circ} \mathrm{C} ; \mathrm{c}: 25^{\circ} \mathrm{C}\right)$. 
trabalho, a redução foi contínua, do início ao fim do armazenamento, e no outro, a redução foi pronunciada do $30 .{ }^{\circ}$ ao $60 .^{\circ}$ dia de armazenamento, coincidindo com paralela elevação no SST, avanço da maturação e início da senescência.

$\mathrm{O}$ pH não apresentou diferenças significativas atribuíveis ao tempo de armazenamento $(p<0,05)$ ou às embalagens/revestimentos, mantendo valores médios de 3,32, 3,46 e 3,40 para os sucos de frutos estocados a $3^{\circ} \mathrm{C}, 8^{\circ} \mathrm{C}$ e $25^{\circ} \mathrm{C}$, respectivamente. Deve-se salientar que os valores de pH não se alteraram na mesma proporção que a AT, haja vista que houve alteração de acidez em função do tempo, sem, entretanto, ocorrer alteração significativa de $\mathrm{pH}$. Tal comportamento deve-se ao efeito tampão dos ácidos orgânicos presentes (CHITARRA e CHITARRA, 2005).

Os teores de SS não foram influenciados pelo tempo de estocagem e pelos recobrimentos utilizados, sendo que os teores médios obtidos foram de 12,02, 11,88 e $11,81^{\circ}$ Brix para os sucos de frutos estocados a $3^{\circ} \mathrm{C}, 8^{\circ} \mathrm{C}$ e $25^{\circ} \mathrm{C}$, respectivamente. Brackmann et al. (1999) e Kluge et al. (2007), trabalhando com laranjas Valência, também não constataram diferenças estatísticas significativas no teor de SS durante 60 dias de armazenamento. Para Cantillano et al. (2009), o teor de SS de laranjas Salustina apresentou discreta diminuição entre 30 e 90 dias de armazenamento, porém sem haver diferenças entre os quatro tipos de revestimentos testados: controle; ceras associadas com fungicidas; associação de ceras, resinas vegetais e fungicidas, e filme polimérico.

Os teores de açúcares nos frutos controle e com diferentes revestimentos/embalagem também não se alteraram durante o armazenamento em diferentes temperaturas, mantendo valores médios de 8,71, 9,10 e $8,63 \mathrm{~g} 100 \mathrm{~mL}^{-1}$ para frutos estocados a $3^{\circ} \mathrm{C}, 8^{\circ} \mathrm{C}$ e $25^{\circ} \mathrm{C}$, respectivamente. Isto confirma o descrito por Chitarra e Chitarra (2005), ou seja, que os frutos cítricos, por serem não climatéricos, apresentam modificações mínimas no conteúdo de açúcares durante o armazenamento e, por isso, devem ser colhidos quando já atingiram a maturidade fisiológica. No armazenamento de laranjas Folha Murcha, Todisco et al. (2012) não constataram variações no teor de açúcares redutores, mas verificaram alterações no teor de açúcares totais, o que foi atribuído à imaturidade dos frutos colhidos.

Frutos armazenados a $3^{\circ} \mathrm{C}, 7^{\circ} \mathrm{C}$ e $25^{\circ} \mathrm{C}$ tiveram valores médios de ácido ascórbico de 46,31, 44,57 e 41,84 mg $100 \mathrm{~mL}^{-1}$, respectivamente, os quais foram mantidos constantes durante o período de armazenamento dos mesmos, sem influência de embalagens/recobrimentos. Kluge et al. (2002) confirmaram que poucas alterações no conteúdo vitamínico dos frutos ocorrem no armazenamento de frutos inteiros, a menos que haja processamento, como é o caso dos produtos minimamente processados.
Vários estudos demonstraram a não alteração do teor de AA ou a ocorrência de pequena perda, geralmente não significativa, durante o armazenamento de frutos cítricos sob diferentes condições (CERETTA et al., 1999; RAPISARDA et al., 2001; VALE et al., 2006). Em contrapartida, alguns trabalhos indicam redução nos teores de AA, como observado em tangerinas Ponkan (LIMA et al., 1999), laranja Valência (KLUGE et al., 2007) e laranjas Salustiana (CANTILLANO et al., 2009).

Verificou-se também que quanto maior a temperatura de armazenamento, menor foi o teor médio de AA nos frutos. Frutos expostos à maior temperatura devem ter iniciado mais precocemente sua senescência, consumindo o ácido ascórbico em reações oxidativas (GARDNER et al., 2000).

Sabe-se que boa parte das transformações pelas quais os frutos de laranja Champagne passaram, durante o armazenamento sob condição de ambiente ou refrigeração, está restrita à parte externa do fruto, com poucas alterações nas características do suco. Isso pode ser justificado pelo fato de que frutos não climatéricos, como os citros, apresentarem apenas o sistema 1 de produção de etileno, isto é, com produção deste hormônio muito baixa (VENDRELL e PALOMER, 1997). O etileno, em frutos não climatéricos, está envolvido apenas em alguns eventos associados à maturação, como a degradação da clorofila da casca, em que o etileno aumenta a atividade da clorofilase, enzima responsável pela catálise da molécula de clorofila (GOLDSCHMIDT, 1997; JACOMINO et al., 2003).

Embora não se tenham constatadas variações significativas nos atributos químicos dos frutos em função do tempo e das embalagens, deve-se considerar que a perda de massa fresca pelos frutos, quando superior a $10 \%$, inviabiliza ou prejudica sua comercialização in natura, de modo que o investimento em embalagens adequadas pode garantir um produto com melhor qualidade.

\section{Conclusões}

Os frutos sem embalagem e os revestidos com fécula de mandioca a 2 e $4 \%$ tiveram maior perda de massa ao longo do período de armazenamento. As temperaturas de refrigeração, associadas com maiores UR, proporcionaram menores perdas de massa em frutos sem embalagem, nos revestidos com filme comestível à base de fécula de mandioca e nos envolvidos com filme de PVC. Não foram constatadas variações significativas para a maioria dos atributos químicos dos frutos em razão do tempo de armazenamento e das embalagens. A utilização do armazenamento refrigerado a $3^{\circ} \mathrm{C}$ associado a $\mathrm{AM}$, por meio de filmes de PVC e polietileno, proporcionou a conservação das características físico-químicas do fruto e de seu suco até o $600^{\circ}$ dia de armazenamento. 


\section{Referências}

ALLEONI, A. C. C.; JACOMINO, A. P.; ROSA, A. S. Recobrimento de Laranja 'Pêra' com Filme de Concentrado Protéico de Soro de Leite Associado a Plastificantes. Pesquisa Agropecuária Brasileira, Brasília, v. 41, n. 8, p. 1221-1226, 2006. http://dx.doi. org/10.1590/S0100-204X2006000800002

AQUINO, S. D.; ANGIONI, M.; SCHIRRU, S.; AGABBIO, M. Quality and Physiological Changes of Film Packaged 'Malvasio' Mandarins During Long Term Storage. LWT - Food Science and Technology, London, v. 34, n. 4, p. 206-214, 2001.

ASSMANN, A. P.; CITADIN, I.; KALICZ, C. A.; LOCATELLI, M. C.; DANNER, M. A. Armazenamento de caqui cv. 'Fuyu' e laranja cv. 'Pêra' em Atmosfera Modificada Sob Diferentes Temperaturas. Synergismus Scyentifica UTFPR, Pato Branco, v. 1, n. 1-2-3-4, p. 133-143, 2006.

BRACKMANN, A.; PETERLE, M. E.; PINTO, J. A. V.; WEBER, A.; SAUTTER, C. K.; EISERMANN, A. C. Temperatura e Umidade Relativa na Qualidade da tangerina "Montenegrina" Armazenada. Ciência Rural, Santa Maria, v. 38, n. 2, p. 340-344, 2008. http://dx.doi.org/10.1590/S0103-84782008000200007

BRACKMANN, A.; LUNARDI, R.; DONAZZOLO, J. Frigoconservação e Controle de Podridões em Laranja "Valência". Ciência Rural, Santa Maria, v. 29, n. 2, p. 247-251, 1999. http://dx.doi.org/10.1590/S0103-84781999000200010

CANTILLANO, R. F. F.; CASTAÑEDA, L. M. F.; CASTRO, L. A. S.; TREPTOW, R. O. Qualidade Pós-Colheita de Laranjas cv. Salustiana Sob Atmosfera Modificada Durante o Armazenamento Refrigerado. Pelotas: Embrapa Clima Temperado, 2009. 31 p. (Boletim de Pesquisa e Desenvolvimento, 90).

CERETTA, M.; GONÇALVES, E. D.; DUTRA, L. F.; RINALDI, M. M.; ROMBALDI, C. V. Filme de Polietileno e Cera na Qualidade da Laranja "Valência" Frigoarmazenada. Revista Brasileira de Agrociência, Pelotas, v. 5, n. 1, p. 35-37, 1999.

CHITARRA, M. I. F.; CHITARRA, A. B. Pós-Colheita de Frutas e Hortaliças: Fisiologia e Manuseio. 2. ed. Lavras: ESAL: FAEPE, 2005. $783 \mathrm{p}$.

ERKAN, M.; PEKMEZCI, M.; WANG, C. Y. Hot Water and Curing Treatments Reduce Chilling Injury and Maintain Post-Harvest Quality of "Valencia" Oranges. International Journal of Food Science and Technology, Malden, v. 40, n. 1, p. 91-96, 2005. http://dx.doi.org/10.1111/j.1365-2621.2004.00912.x

FIORAVANÇO, J. C.; MÂNICA, I. Armazenamento de Frutas Cítricas em Temperatura Controlada. Cadernos de Horticultura, Porto Alegre, v. 2, n. 2, p. 1-8, 1994.

FISCHER, I. H.; FERREIRA, M. D.; SPÓSITO, M. B.; AMORIM, L. Citrus Postharvest Diseases and Injuries Related to Impact on Packing Lines. Scientia Agricola, Piracicaba, v. 66, n. 2 , p. 210-217, 2009.
GALED, G.; FERnÁNDEZ-VALLE, M. E.; MARTÍnEZ, A.; HERAS, A. Application of MRI to Monitor the Process of Ripening and Decay in Citrus Treated With Chitosan Solutions. Magnetic Resonance Imaging, v. 22, n. 1, p. 127-137, 2004. PMid:14972402. http://dx.doi.org/10.1016/j.mri.2003.05.006

GARDNER, P. T.; WHITE, T. A. C.; MCPHAIL, D. B.; DUTHIE, G. G. The Relative Contribuitions Of Vitamin C, Carotenoids and Phenolic to the Antioxidants Potential of Fruits Juices. Food Chemistry, Barking, v. 68, n. 4, p. 471-474, 2000.

GOLDSCHMIDT, E. E. Ripening of Citrus and Other Non-Climateric Fruits: a Role For Ethylene. Acta Horticulturae, Leuven, n. 463, p. 325-334, 1997.

GORRIS, L. G. M.; PEPPELENBOS, H. W. Modified Atmosphere and Vacuum Packaging to Extend the Shelf Life of Respiring Food Products. Hortechnology, Alexandria, v. 2, n. 3, p. 303-309, 1992.

HAGENMAIER, R. D. The Flavor of Mandarin Hybrids With Different Coatings. Postharvest Biology and Technology, Amsterdam, v. 24, n. 1, p. 79-87, 2002. http://dx.doi.org/10.1016/ S0925-5214(01)00121-1

HENRIQUE, C. M.; CEREDA, M. P. Uso de Ethephon e Fécula de Mandioca na Conservação Pós-Colheita de Limão Siciliano. Revista de Biologia e Ciências da Terra, Campina Grande, v. 7, n. 1, p. 99-106, 2007

HORWITZ, W. (Ed.). Official Methods of Analysis of the Association of Official Analytical Chemists. Gaithersburg: AOAC, 1997, p. 16-17. v. 2.

INSTITUTO BRASILEIRO DE FRUTAS - IBRAF. Estatísticas. 2010. Disponível em: <http://www.ibraf.org.br/estatisticas/ est_frutas.asp>. Acesso em: 14 jul. 2014.

INSTITUTO ADOLFO LUTZ - IAL. Métodos Físico-Químicos para Análise de Alimentos. 4. ed. São Paulo: IAL, 2005. 1018 p.

INSTITUTO BRASILEIRO DE QUALIDADE EM HORTICULTURA - HORTIBRASIL. Programa Brasileiro Para Modernização da Horticultura. Normas de Classificação de Citros de Mesa. São Paulo: CEAGESP, 2011.

JACOMINO, A. P.; MENDONÇA, K.; KLUGE, R. A. Armazenamento Refrigerado de Limões 'Siciliano' Tratados com Etileno. Revista Brasileira de Fruticultura, Jaboticabal, v. 25, n. 1, p. 45-48, 2003.

JOMORI, M. L. L.; KLUGE, R. A.; JACOMINO, A. P.; TAVARES, S. Conservação Refrigerada de Lima Ácida "Tahitî": Uso de 1metilciclorpopeno, Ácido Giberélico e Cera. Revista Brasileira de Fruticultura, Jaboticabal, v. 25, n. 3, p. 406-409, 2003.

KE, D.; KADER, A. A. Tolerance of 'Valencia' Oranges to Controlled Atmospheres, as Determined by Physiological Responses and Quality Attributes. Journal of American Society Horticultural Science, Alexandria, v. 115, n. 5, p. 779-783, 1990. 
KESTER, J. J.; FENNEMA, O. Edible Films and Coatings: a Review. Food Technology, Chicago, v. 40, v. 12, p. 47-59, 1986.

KLUGE, R. A.; JOMORI, M. L. L.; EDAGI, F. K.; JACOMINO, A. P.; AGUILA, J. S. Danos de Frio e Qualidade de Frutas Cítricas Tratadas Termicamente e Armazenadas sob Refrigeração. Revista Brasileira de Fruticultura, Jaboticabal, v. 29, n. 2 , p. 233-238, 2007.

KLUGE, R. A.; NACHTIGAL, J. C.; FACHINELLO, J. C.; BILHALVA, A. B. Fisiologia e Manejo Pós-Colheita de Frutas de Clima Temperado. 2. ed. Campinas: Livraria e Editora Rural, 2002. 214 p.

LATADO, R. R.; TOGNATO, P. C.; SILVA-STENICO, M. E.; NASCIMENTO, L. M.; SANTOS, P. C. Acúmulo de Antocianinas e Características Físicas e Químicas de Frutos de Laranjas Sanguíneas Durante o Armazenamento a Frio. Revista Brasileira de Fruticultura, Jaboticabal, v. 30, n. 3, p. 604-610, 2008.

LERMEN, F. H.; COELHO, T. M.; ASSAD FILHO, N. Conservação da Laranja na Aplicação de Amido Modificado Hidrofóbico. Revista Verde, Mossoró, v. 7, n. 4, p. 39-44, 2012.

LIMA, L. C.; VILAS BOAS, E. V. B.; REIS, J. M. R.; CHITARRA, A. B. Qualidade dos Frutos de Tangerineiras 'Ponkan' (Citrus reticulata blanco), Armazenados sob Temperatura Ambiente. Revista da Universidade de Alfenas, Alfenas, v. 5, p. 27-31, 1999.

MALGARIM, M. B.; CANTILLANO, R. F. F.; TREPTOW, R. O. Conservação de Tangerina cv. Clemenules Utilizado Diferentes Recobrimentos. Acta Scientiarium Agronomy, Maringá, v. 29, n. 1, p. 75-82, 2007.

MANNHEIN, C. H.; SOFFER, T. Permeability of Different Wax Coatings and Their Effect on Citrus Fruit Quality. Journal of Agricultural and Food Chemistry, Davis, v. 44, n. 3, p. 919-923, 1996.

NASCIMENTO, L. M.; CUZIN, J.; MARTINS, A. B. G. Efeito do Etileno na Qualidade de Frutos da Laranjeira Pera Armazenados sob Diferentes Temperaturas. Revista Iberoamericana de Tecnológia Postcosecha, Sonora, v. 8, n. 1, p. 7-16, 2006.

NASCIMENTO, L. M.; SANTOS, E. J.; LEONEZI, A. L. Eficiência da Aplicação de Diferentes Doses de Fungicidas em Lima Ácida Tahiti, Laranja Pêra e Tangor Murcott para o Controle de Penicillium digitatum. Revista Iberoamericana de Tecnologia Postcosecha, Sonora, v. 7, n. 1, p. 41-47, 2005.

OLIVEIRA, M. A.; CEREDA, M. P. Efeito da Película de Mandioca na Conservação de Goiabas. Brazilian Journal of Food Technology, Campinas, v. 2, n. 1-2, p. 97-102, 1999.

OLIVEIRA, S. M. A.; TERAO, D.; DANTAS, S. A. F.; TAVARES, S. C. C. H. Patologia Pós-Colheita: Frutas, Olerícolas e Ornamentais Tropicais. Brasília: Embrapa Informação Tecnológica, 2006. $855 \mathrm{p}$.
PORAT, R.; WEISS, B.; COHEN, L.; DAUS, A.; AHARONI, N. Reduction of Postharvest Rind Disorders in Citrus Fruit by Modified Atmosphere Packaging. Postharvest Biology and Technology, Amsterdam, v. 33, n. 1, p. 35-43, 2004. http:// dx.doi.org/10.1016/j.postharvbio.2004.01.010

RAPISARDA, P.; BELLOMO, S. E.; INTELISANO, S. Storage Temperature Effects on Blood Orange Fruit Quality. Journal of Agricultural and Food Chemistry, Davis, n. 49, p. 3230-3235, 2001.

SINGH, K. K.; REDDY, B. S. Post-Harvest Physico-Mechanical Properties of Orange Peel and Fruit. Journal of Food Engineering, Cesena, v. 73, n. 2, p. 112-120, 2006.

TODISCO, K. M.; CLEMENTE, E.; ROSA, C. I. L. F. Conservação e Qualidade Pós-Colheita de Laranjas "Folha Murcha" Armazenadas em Duas Temperaturas. Revista em Agronegócios e Meio Ambiente, Maringá, v. 5, n. 3, p. 579-591, 2012.

TOGGRUL, H.; ARSLAN, N. Carboxymethyl Cellulose From Sugar Beet Pulp Cellulose as a Hydrophilic Polymer in Coating of Mandarin. Journal of Food Engineering, v. 62, n. 3, p. 271-279, 2004. http://dx.doi.org/10.1016/S0260-8774(03)00240-1

VALE, A. A. S.; SANTOS, C. D.; ABREU, C. M. P.; CORRÊA, A. D.; SANTOS, J. A. Alterações Químicas, Físicas e Físico-Químicas da Tangerina 'Ponkan' (Citrus reticulata Blanco) Durante o Armazenamento Refrigerado. Ciência e Agrotecnologia, Lavras, v. 30, n. 4, p. 778-786, 2006.

VALENCIA-CHAMORRO, S. A.; PÉREZ-GAGO, M. B.; RÍO, M. A.; PALOU, L. Effect of Antifungal Hydroxypropyl Methylcellulose (HPMC)-lipid Edible Composite Coatings on Postharvest Decay Development and Quality Attributes of Cold-Stored 'Valencia' Oranges. Postharvest Biology and Technology, Amsterdan, v. 54, n. 2 , p. $72-79,2009$.

VENDRELL, M.; PALOMER, X. Hormonal Control of Fruit Ripening in Climacteric Fruits. Acta Horticulturae, Leuven, v. 463, p. 325-334, 1997

VIEITES, R. L.; ARRUDA, M. C.; GODOY, L. J. G. Utilização de Cera e Película de Fécula no Armazenamento da Laranja Pera sob Refrigeração. Semina: Ciências Agrárias, Londrina, v. 17, n. 1, p. 83-88, 1996.

ZANCHI, V. V.; COSTA, E. F.; SCHWANTES, F.; XAVIER, L. F. Desempenho das exportações brasileiras de frutas in natura (1996-2007): uma análise sob a ótica do modelo gravitacional. Teoria e Evidência Econômica, Passo Fundo, v. 19, n. 41, p. 9-34, 2013. 